\title{
Capitalization Roles in Subtitled Igbo Movies: The Translator's Aid
}

\author{
Christopher Chinedu Nwike \\ Department of Linguistics, Igbo and Other Nigerian Languages, University of Nigeria, Nsukka, Nigeria \\ Christopher Uchenna Agbedo \\ Department of Linguistics, Igbo and Other Nigerian Languages, University of Nigeria, Nsukka, Nigeria \\ Ndubuisi Ihechinyere Ebulu \\ Department of Linguistics, Nnamdi Azikiwe University, Awka, Nigeria
}

\begin{abstract}
The study revolves around capitalization roles in subtitled Igbo movies: The translator's aid by focusing on the relevance of the translator in making sure that the right information is appropriated. The study shows that capitalization is the writing of a word of a particular language with its first letter in uppercase or big letters while the remaining letters in lowercase or small letters. However, capitalization error is involved with wrong use or application of capitalization in written utterances of a particular language. In other to have the right message in the movie used for the study, this research adopted the methodology of description in its design in order to account for the movie used for the study. In doing this, the researcher played and replayed the movie in order to describe the information correctly and also, recognizing the different places capitalizations are used or should set in. The study finds out that there is need to avoid capitalization errors in any written information and concludes by recommending the translators services or aid, as it will help to make available the supposed and worth having information in the target language.
\end{abstract}

Index Terms - capitalization, grammar and subtitle

\section{INTRODUCTION}

Capitalization is an essential element in every written information of a particular language, as it brings about discrepancy between plain words and proper name allusions or where possibly should start a written information in a sentence. One can say that capitalization is taken to be the writing of a word of a particular language with its first letter in uppercase or big letters while the remaining letters in lowercase or small letters. According to Young and Young and Fry (2008), writing is involved with one of the main skills that second language learners of a particular language find difficulty in. However, one of the areas that they find difficult in the process of writing compositions or anything is the correct use of the capital letters or upper case. So, capitalization error is involved with wrong use or application of capitalization in written utterances of a particular language. In this study, let's say that capitalization is a practice that can be done in textual and audio visual or media translations or screen translations. Translation is an exercise that is involved with information transfer. In the field of translation, it is very important to note that one does not translate or transfer in a language that he is not competent in, or language that he barely understands as faithful translation according to Nida (1964) states that translation involves having the equivalence of the source information in the target language while maintaining its meaning. As capitalization is one of the elements of the things that will make the transferred information to seem as the original information, it is very pertinent that a translator of the source information should understand the different places capitalization is applied. Transferred information which seem original to the target audience is what this study sees as a faithful and true translation because translation involves enough skill in order to perform well in the information transfer. So, being an exercise that involves transposition of data, Nwike (2019) believes that it involves transfer of the original meaning of the source information in the target language. So, while translating any information thus textual (book transfer) or paratextual (non book transfer), the translator should understand the different techniques of capitalization application as to avoid confusing the target language audience who may want to learn the language from differentiating between proper name allusions and other places where capitalization should originally set in. This is to say that when capitalization is not being applied well in a language, there may be a clear lose of information.

According to Young and Fry (2008), there are rules that govern the use of capitalization in the English language as well as some other languages of the world. Upon this, the rules show that capitalization is done on the first word of a quoted or written sentence(s). For instance, 'Nkechi, treat him as you would your own son.' Again, while writing in any language, it is clear to state that a proper noun should be capitalized hence, River Niger. More so, one can capitalized a person's title especially when it preceded the name. However, one is not supposed to capitalize when the title functions as a description that follows the name. For instance, Chairlady Ihechinyere Ndubuisi and Sir. Chinedu Nwike, or the 
chairlady of the congress, will address us in the morning. Again, Young and Fry (2008) states that one can capitalize the person's title when it follows the name on the address or signature line - Prof. Chris, Chairwoman as well as capitalizing the titles of the high-ranking government officials. This is done when it is used before their names, but not to capitalize the civil title if it is used instead of the name. For instance, according to Young and Fry (2008), the special task forces are; The governors, lieutenant governors, and attorney generals - Governor Unigwe, Lieutenant Governor Unigwe, Attorney General Unigwe, and Senators Stella and Juliet will travel. However, one can capitalize allusions or any title when used as a direct address such as Will you pray for me, Reverend? Additionally, Young and Fry (2008) states that one can capitalize the points of a compass only when they refer to specific regions like I have had three doctors visit from the Northern Nigeria. Again, the first and last words of titles of publications are capitalized irrespective of their parts of speeches. Other words within titles are capitalized, including the short verb forms "Is, Are, and Be." In other words, Young and Fry (2008) states that there is an exception to this previously related information as you do not capitalize little words within titles such as "a, an, the, but, as, if, and, or, nor, or prepositions," not minding their length. For instance, The Day of Settlement

In connection with the above, Young and Fry (2008) state that when 'federal or state' is used as part of an official agency name or in government documents where these terms represent an official name. Again, Young and Fry (2008) are of the view that one can capitalize if they are being used as general terms hence, you may use lowercase letters. For instance, The National Ministry of Account collects taxes/ I visited three states during the ASUU strike. Again, capitalization can be done on words such as "department, bureau, and office" - The Department of Linguistics has role to play in the faculty programs. The Bureau is finding its administrative role to be challenging. Capitalize the first word of a salutation and the first word of a complimentary salutation in a language - My dear Mr. Timothy/Very truly yours. In other words, capitalize words derived from proper nouns such as I must take English and maths. According to Young and Fry (2008), 'English' is capitalized because it comes from the proper noun 'England', but math does not come from 'Mathland.' Furthermore, after a sentence ending with a colon, Young and Fry (2008) are of the view that one does not capitalize the first word if it begins with a list - These are my favourite foods: okpa, ayaraya oka, and akpu mmiri. Do not capitalize when only one sentence follows a sentence ending with a colon - I love Prof. Agbedo's writing: his book, Multilingualism and National Development in Nigeria was beautiful.

Based on the above information, having known what capitalization is all about and some of the things that revolves around it including the rules that govern it although, not an end to capitalization information, this study hinges on the role of capitalization in the subtitled Igbo home movies: The translator's aid in order to practically address the wrong capitalization seen in the movie titled Onye bu nna $\mathrm{m}$. In doing this, the objective of the study hinges on shedding light on the role of capitalization in the subtitled Igbo home movie used for the study as its signification will help in cubing off much errors concerning wrong capitalized subtitles in the media houses and any written information in order to enable a foreign language learner of the language to learn better.

\section{THEORETICAL STUDIES}

In an era where cross fertilization of ideas and culture are important, it is good to be transferring information in a supposed form as it tells a lot about the original information. Knowing fully well that information transfer involves the transference of the most accurate information into another language as it involves written and not intersemiotic, all the necessary ingredients that will accentuate the relevance of good production should be taking into consideration, capitalization involved. Based on this premise, a good translator should understand capitalization application well since translation deals with involvement of another culture. Translation has helped in different ways in documenting many works into other languages, while retaining the semantic properties of the original information in the target language. In lieu of this, the theory of Jakobson (1959) believes on the intetrsemiotic way of approaching translation which on this ground, the theory pointed out that anyone who engages in translation study should first try as much as possible to grab the information of the source text and renders it the same by having the equivalent version in the target text and culture. This is because, according to Jakobson (1959), translation involves having same information in two or more languages. Although, due to the differences in language formations, one who translates may be faced with not having the equivalence of the source information in the target language and as such, it gives rise to what one can rightly call a situational equivalence. Herein, a grammatical or cultural device is formed to replace the encountered term, word or phrases of the source text which from that point, forms part of the vocabulary of the target language and culture as it will replace an information of the source text in the target text. But for Jakobson (1959), when the situation of not having a replica or equivalence of the source information in the target language arises, the words of the original should be replaced with loan translation or loan words, semantic shifts or neologisms and circumlocution. More so, he added that in a situation where there is no form of literal replacement or equivalence for words of the original information, the translator is opportune to adopt any convenient and most suitable way or form of rendering the text information into the target language in order to have same information documented in the target text and culture.

Additionally, the work of Venuti (2000) sees translation as the way of relating a foreign text through establishment of relationship of identity. From this point, he came up with two forms of equivalence thus, pragmatic equivalence and formal equivalence in translation which in the process tries to bring to the fore the discrepancy between the two. However, according to Venuti (2000) the pragmatic equivalence is the type of equivalence that is strongly hinged on the 
individual who receives the information of the original text. On the other hand, the main focus of the formal equivalence is to make up foreign text through approximation of the linguistic and cultural features. On this ground, the pragmatic equivalence respects the culture of the target language while the formal equivalence pays much attention to the source text by respecting its linguistic and cultural values without considering its effect on the target audience that will receive the translated information.

On the part of Catford (1965), translation equivalence takes place where the information of the source text and the target language are of a great resemblance thus having a replica of the original in the target text and culture. From this point, Catford forms a concept called a 'shift' which can be called a departure or movement from the source language to the target language. This shift is what he divided into two thus, level shift and category shift. A level shift involves the situation where the linguistic or grammatical unit of the source information is available in the target language while the category shift is divided into types in order to suit different situations. According to Catford (1965), the four types are class-shifts, structure-shifts, intra-system shifts and unit-shifts. Categorically, Catford posits that these shifts are very important in establishing a good and working equivalence of the original information and received information, hence, translated text. In maintaining the exactness of the source information in the target text as pointed out by Catford and Venuti, translations of allusions are to be taken seriously. So, since the allusions deal on proper names, Richards (1985) then proposes that a proper name is a name of a particular person, place or thing. And so, they are spelled with a capital letter while playing essential roles in written information. So, during the information transfer, personal names PNs should be giving enough attention as it can be seen as the setting, social status and nationality of characters which on a great extent demands attention during rendition into a foreign language - target language. While capitalizing proper names in translation, Hervey and Higgins (1986) state that it can take shape in the following forms thus:

i. Either the name is taken over unchanged from the source text to the target text

ii. It can be adopted to conform to the phonic/graphic conventions of the target language.

Based on the above highlights, Hervey and Higgins (1986) called the first one exotism which is equivalent to a literal translation that involves no cultural transposition, while the second one is called transliteration.' Essentially, aside from the above information, they came up with another procedure a translator can use as bedrock during rendition of movie or book hence, cultural transplantation. Cultural transplantation is what Hervey and Higgins (1986) see as replacing the source language names with the indigenous target language names that shares no same literal equivalents but, with a similar cultural meanings or flavour. In line with the following, Newmark (1988) came up with his own idea of translating PNs. People's first and surnames are transferred, and it helps to preserve nationality while assuming that their names have no connotations in the text (Newmark, 1988). However, the procedure of the transference cannot be ascertained to be effective where the implying meaning and connotations are significant. For Newmark, in a situation where there are names that bear connotations, it implies that they require a specific strategy for being translated. This is to say that the procedure for such problem is to first translate the word that underlies the source language proper name into the target language and then naturalize the translated word back into a new source language proper name (Newmark, 1988). However, in connection with the previous belief, it is discovered that there is always a limitation to this and it is evident in the sense that it is only useful for personal names PNs. This is because, the Newmark ideas did not allow the target audience to have a taste or feel the aesthetics of the source text. According to Newmark (1988) this can be done only on the condition where the character's name is not yet current in the target audience's readership. In other words, in trying to strike a clear balance and bringing solution to this, it is discovered that there are possible strategies that translators can adopt in situations under discourse - proper name allusions. According to Leppihalme (1997), they are:

i. Replacement of the name by another:

a. replacing the name by another SL name.

b. replacing the name by a TL name

ii. Omission of the name:

a. omitting the name, but transferring the sense by other means, for instance by a common noun

b. omitting the name and the allusion together.

iii. Retention of the name

a. using the name as such.

b. using the name, adding some guidance.

c. using the name, adding a detailed explanation, for instance, a footnote.

Aside from the above strategies of Leppihalme (1997) towards effective translation of proper name allusions, the translators needed a guide towards translating key-phrase allusions, and to avoid such problems anytime they come in translation, Leppihalme (1997) came up with a nine strategy for the effective translation of the key-phrase allusions. According to Leppihalme (1997), they are:

i. Use of a standard translation

ii. Minimum change, that is, a literal translation, without regard to connotative or contextual meaning,

iii. Extra allusive guidance added in the text,

iv. The use of footnotes, endnotes, translator's notes and other explicit explanations not supplied in the text but explicitly given as additional information, 
v. Stimulated familiarity or internal marking, that is, the addition of intraallusive allusion,

vi. Replacement by a TL item,

vii. Reduction of the allusion to sense by rephrasing,

viii. Re-creation, using a fusion of techniques: creative construction of a passage which hints at the connotations of the allusion or other special effects created by it,

ix. Omission of the allusion.

In continuance with the above information, it can now be said that the problem of translating the key-phrase allusions anytime translators encounter it during any form of information transfer is solved. However, due to the other form of problems inherent in translational exercises as regards to textual translation, in order to bring an end to the possible impeding translation challenges, there are goals that are put up on this regard that the translator will look up to. On this, Chesterman (1997) states the following thus:

1. It involves text manipulation

2. It must be applied to the process

3. it must be goal oriented

4. It must be problem centered

5. It must be applied consciously

6. It must be inter-subjective - must be empirical and understandable for the readers not the person who used them.

Based on the above outlines, Chesterman (1997) implies that at first, one shall read and comprehend a text. Second, one shall analyse the discrepancy between the source and the target texts, and one shall decide on the kind of strategies to use. And finally, one shall produce the equivalent text in the target language. Again, there are other forms of strategies that the translators can adopt while trying to have the equivalent original information in the target language. According to Chesterman (1997), they are:

1. Semantics,

2. Syntactic, and

3. Pragmatic changes.

Conclusively, when a translator tries to use the above strategies when he or she encounters problems during information transfers, it is very clear that the problems are solved because it will help in the transfer which will lead to an explicit and accurate understanding of culture specific concepts during translation as well as translating as supposed of the proper name allusions. Aside from all the above discussed views of translator's aid, there are basis that are mapped out to follow or to apply in any situation of the translational exercise, and it is the translation theory.

\section{Toury's Descriptive Translation Study}

The work of Toury (1984) supports perspective systematic descriptive analysis of any work to be translated. This is to say that theories of translation can only be developed on the basis of descriptive study of translation. For Toury (1984), it arises in the literary polysystem of the culture in which they exist. However, polysystem according to EvenZohar (1979) is an aggregate of literary systems and a means to account for the way in which literature revolves a given culture. On the assumed belief of Toury (1984), he avoids taking a prescriptive approach to his descriptive analysis of translation.

In connection with the review above, this study shall focus on the work of Toury (1984) as well as Young and Fry (2008) as a yardstick or frameworks of the study as their focus are exactly what that will bring out the aesthetics of this study of the movie titled Onye bu nna m.

\section{ReSEARCh Methodology}

From the study, it is discovered that the most suitable methodology to adopt is use of description in its design in order to account for the movie used for the study. In doing this, the researcher shall play and replay the movie in order to describe the information correctly and also, recognizing the different places capitalization are used or should set in.

\section{DATA PRESENTATION}

This part of the study presents the capitalization errors in the subtitled Igbo movie. The main essence of the study is to shed light on the role of capitalization in the subtitled Igbo home movie used for the study. These errors are gotten from the subtitled Igbo movies used for the study. The errors are presented in the table below thus:

\begin{tabular}{|l|l|}
\hline Asụsụ Igbo/Igbo language & Movie subtitled capitalization errors \\
\hline Mụ sịrị gị butuo & I said Calm down \\
\hline Mụ butuo ma mezie gịnị? & I should Calm down and wait to do whar then $\S$ \\
\hline Amaka biko ewela iwe o, ezi enyi m & amaka please don’t get annoyed over what I just said \\
\hline ...hịa o, mmadụ a gaghị egwusakwu gị egwu ọzọ & ...So one cannot joke with you again \\
\hline
\end{tabular}

\section{A. Data Analysis}


This section of the study is involved with the data analysis of the study. It shows the wrong capitalization and its correct subtitles. So, the data analysis of this study is strictly presented and discussed below in the table below based on the objectives of the study - to shed light on the role of capitalization in the subtitled Igbo home movie used for the study.

\section{B. Discussion of Capitalization Errors}

This part discuses the information in the table below as they are related or used in the study. They are as follows:

\begin{tabular}{|l|l|l|}
\hline Igbo language & Movie subtitled capitalization errors & Correct capitalization \\
\hline Mụ sịị gị butuo & I said Calm down & I said calm down \\
\hline Mụ butuo ma mezie gịnị? & I should Calm down and wait to do whar then § & I should calm down and wait to do what then? \\
\hline $\begin{array}{l}\text { Amaka biko ewela iwe o, ezi } \\
\text { enyi m }\end{array}$ & $\begin{array}{l}\text { amaka please don’t get annoyed over what I just } \\
\text { said }\end{array}$ & Amaka please do not be angry, my good friend \\
\hline $\begin{array}{l}\ldots \text {...ịa o, mmadụ a gaghị } \\
\text { egwusakwu gị egwu ọzọ... }\end{array}$ & $\ldots$..So one cannot joke with you again... & ...oh, one cannot joke with you again.... \\
\hline
\end{tabular}

Based on the information in the table above, the translator was able to come up with the correct capitalization by the use of the rules propounded by Young and Fry (2008) and the systemic description of Toury (1984) in translation. The thoughts of Toury (1984) helped the translator to retell the exactness of the story line of the original information of actors in the movie used for the study as well as applying capitalization where they are required in a statement with the supposed capitalization. This helped to create a good sense of sameness in the rendition. The sense of capitalization in written information performs several functions which when it's no longer performing the role of capitalization in the sentence or word where it occurred, it will show that something is wrong and the right message will not be rightly presented. Upon this backdrops, an example shall be taking from the above table used to present the different wrong capitalization as well as their correct equivalence in the movie used for the study. For instance, Amaka biko ewela iwe o, ezi enyi $m$ and it was wrongly capitalized with 'amaka please don't get annoyed over what I just said' while the translator rendered it to be Amaka please do not be angry, my good friend. Another example is I said Calm down. Based on this, it is clear that rule of capitalization made available by Young and Fry (2008) is violated and as such, a wrong capitalization is applied in the movie used for the study. In order to combat this problem, the translator subtitled it to be 'I said calm down' and same change occurred in the other data presented in the above table under movie subtitled capitalization errors. However, it is to be said that the translator used thoughts of Young and Fry (2008) and the systemic description of Toury (1984) to retain sameness in the information transfer of the frames - subtitles on the screen in order to be faithful with the information. So, it can be said categorically that the above table have achieved the objective of the study by providing accuracy and shedding light on the role of capitalization in the subtitled Igbo home movie used for the study which helped to avoid meaning lose through the translator's aid.

\section{FINDINGS AND CONCLUSION}

The study discovered that there is need to avoid capitalization errors in any written information as it will help a foreign language learner of the target language to be able to understand every part of available information presented. As one of the reasons why subtitles are done, the study discovered that when talking about proper name allusions, that initial capital starts the name and as such, it makes PN to be different from the other plain words of a particular language in the function it performs in a sentence.

Conclusively herein, this study suggests that people who work in the media houses should engage the translators services or aid as it will help to make available the supposed and worth having information in the secular society in order to avoid capitalization blemishes in a subtitled information of a translated message.

\section{REFERENCES}

[1] Catford, J.C. (1965). A Linguistic theory of translation: An essay in applied linguistics. London: Oxford University Press.

[2] Chesterman, A. (1997). Memes of translation: The spread of ideas in translation theory. Amsterdam: John Benjamins.

[3] Even-Zohar, I. (1979). Polysystem theory. Poetics Today 1, (2), 237-310.

[4] Hervey, S. \& Haggins, I. (1986). Translation studies. Routledge: London.

[5] Jakobson, R. (1959). On linguistics aspects of translation. Britain: Cromwell Press Ltd.

[6] Leppihalme, R. (1997). Culture bumps: An empirical approach to the translation of allusions. Clevedon: Multilingual Matters.

[7] Newmark, P. (1981). Approaches to Translation. Oxford: Pergamon Press,

[8] Newmark, P. (1988). Approaches to translation. Hertfordshire: Prentice Hall.

[9] Nida, E. A. (1964). Toward a science of translation. Leiden: Brill.

[10] Nwike, C. C. (2019). Issues and challenges in translating legal text from English to the Igbo language. M. A Dissertation, Department of Linguistics, University of Nigeria, Nsukka.

[11] Richard, A. (1985). Longman dictionary of applied linguistics. Leiden: Brill.

[12] Toury, G. (1984). Translation, literary translation and pseudotranslation. Comparative criticism. 6, 73-87.

[13] Venuti, L. (Ed.). (2000). The Translation Studies Reader. London and New York: Routledge. 
[14] Young, A. \& Fry, J. (2008). Metacognitive awareness and academic achievements in college students. Journal of the scholarship of teaching and learning, 5(2) 1-10. Retrieved on December 12 $2^{\text {th }}, 2020$ from httpps://eric.ed.gov/?id=EJ854832.

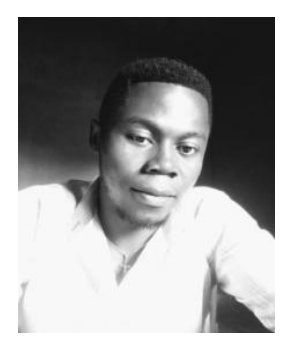

Christopher Chinedu Nwike is a native of Onitsha, Onitsha North Local Government Area of Anambra State. He was born in Ogidi, Anambra State on the $3^{\text {rd }}$ of May. Christopher Chinedu Nwike obtained a Bachelor of Arts degree in Linguistics/Igbo in the department of Linguistics, Igbo and Other Nigerian Languages, University of Nigeria, Nsukka, Enugu State in 2015. Also, he obtained a Master of Arts degree in Translation and Interpreting in the department of Linguistics, Igbo and Other Nigerian Languages, University of Nigeria, Nsukka, Enugu State in 2019.

Currently, Christopher Chinedu Nwike undergoes a doctoral study $(\mathrm{PhD})$ in Translation in the department of Linguistics, Igbo and Other Nigerian Languages, University of Nigeria, Nsukka.

He engages in translation jobs - textual translation and subtitles. He is an Igbo language teacher in Royal Crown Academy Orba Road Nsukka, Enugu State. Mr. Nwike belongs to the Association of Translation Studies in Nigeria (ATSN). He also obtained an academic Merit Award in Honour of Aknu-lbiam As the Best Graduating Student Who Produced the Best Long Easy in Igbo Language in the 2014/2015 Academic Session. His areas of specialisation are Translation and Interpreting while his research interests are semantics and Igbo studies

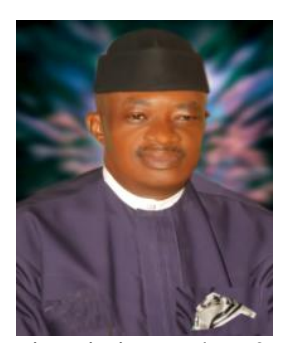

Christopher Uchenna Agbedo was born and brought up in Olido, Elugwu-Ezikeoba, Igbo-Eze North Council Area of Enugu State Nigeria. He studied in the Department of Linguistics and Nigerian Languages, University of Nigeria Nsukka and obtained B.A (Linguistics/Igbo), M.A (Linguistics), PhD (Linguistics) in 1986, 1991 and 1997 respectively. He has been a key player in the university system as a lecturer, supervisor, researcher, mentor, administrator, language development expert and communication strategist, consultant to professional and corporate bodies like National University Commission, National Commission for Colleges of Education, and Joint Admission and Matriculation Board. He is a member of the Senate of the University of Nigeria, member, Senate Entrance Committee, chairman and member of several University, Faculty, and Departmental Committees. He is a Professor of Linguistics, and was immediate past Head of Department, Linguistics, Igbo \& Other Nigerian Languages, University of Nigeria, Nsukka Nigeria. Prof Agbedo has authored over 100 publications, comprising 9 mainline textbooks on language and linguistics, 4 creative works (novels), 80 journal articles, 16 book chapters and 2 edited books and journals. He is a member of professional organisations, including Linguistic Association of Nigeria, Applied Linguistics and Literacy in Africa \& the Diaspora Research Network, American Association for Applied Linguistics, International Pragmatics Association, African Studies Global Virtual Forum, Pennsylvania State University, USA and Fellow, Netherlands Institute of Advanced Studies (NIAS-KNAW). He has attended over 28 local, national, and international conferences, seminars, and workshops. He has successfully supervised over 100 undergraduate long essays, 38 Master of Arts dissertations, and 19 doctoral theses. He is an external examiner to over 10 federal and state universities and external assessor of professorial appointments to several federal and state universities. He is currently on the editorial boards of about 10 local and international journals as founding editor, editor-in-chief, editorial consultant, and peer review editor. He has 10 local and international prizes and awards. His areas of specialisation are sociolinguistics and psycholinguistics; his research interests include critical applied linguistics, pragmatics, discourse analysis, translation/interpretation, child communication disorders and documentary linguistics.

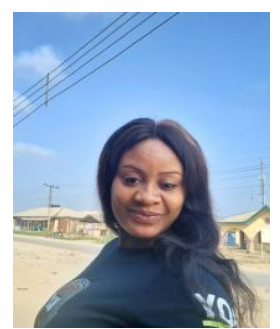

Ndubuisi Ihechinyere Ebulu is a Master's Degree Student of Linguistics at Nnamdi Azikiwe University, Awka. Her academic goal and interest lie in her desire to painstakingly use all within her limit to see that the Igbo Language is sustained and preserved in global politics of knowledge and network. Ndubuisi's current research focuses on technical translation.

Prior to the above background, she has researched on the Igbo proverbs: Its contextual and literal meanings and roles in child training during her diploma program in 2012, as well as the place of Indigenous Nigerian Languages (using the Igbo Language as a case study) in the media; this formed the basics for her academic work in 2015 during her first degree (B.A Linguistics) at the University of Nigeria, Nsukka.

Ndubuisi is a member of Linguistics Association of Nigeria (LAN) and has received a certificate of participation in 2015 during the association's annual conference. 